\title{
WNKs: protein kinases with a unique kinase domain
}

\author{
Chou-Long Huang ${ }^{1,3}$, Seung-Kuy Cha', \\ Hao-Ran Wang ${ }^{1}$, Jian $\mathrm{Xie}^{1}$ and Melanie H. Cobb ${ }^{2}$ \\ ${ }^{1}$ Department of Medicine \\ 2Department of Pharmacology \\ University of Texas \\ Southwestern Medical Center \\ Dallas, Texas 75390 , USA \\ ${ }^{3}$ Corresponding author: Tel, 1-214-648-8627; \\ Fax, 1-214-648-2071; E-mail, chou-long.huang @utsouthwestern.edu
}

\section{Accepted 23 July 2007}

Abbreviations: ENaC, epithelial sodium channel; IGF, insulin-like growth factor; KCC, potassium-chloride cotransporter; NCC, sodium-chloride cotransporter; Nedd4, neural precursor cell-expressed, developmentally down-regulated 4; NKCC, sodium-potassium-chloride cotransporter; OSR1, oxidative stress-responsive kinase; PHA II, pseudohypoaldosteronism type II; ROMK, renal outer medullary potassium channel; SGK, serum and glucocorticoid-inducible kinase; SLC12, solute carrier family 12; SPAK, sterile20-related, proline-, alanine-rich kinase; WNK, with-no-lysine (K)

\begin{abstract}
WNKs (with-no-lysine [K]) are a family of serine-threonine protein kinases with an atypical placement of the catalytic lysine relative to all other protein kinases. The roles of WNK kinases in regulating ion transport were first revealed by the findings that mutations of two members cause a genetic hypertension and hyperkalemia syndrome. More recent studies suggest that WNKs are pleiotropic protein kinases with important roles in many cell processes in addition to ion transport. Here, we review roles of WNK kinases in the regulation of ion balance, cell signaling, survival, and proliferation, and embryonic organ development.
\end{abstract}

Keywords: genome, human; hyperkalemia; hypertension; neoplasms; protein kinases; pseudohypoaldosteronisms; WNK1 protein, human

\section{Introduction}

WNKs (with-no-lysine [K]) are serine-threonine protein kinases that have unusual protein kinase domains due to the unique placement of the catalytic lysine relative to all other protein kinases (Xu et al.,
2000). For all other protein kinases, a conserved catalytic lysine is present in sub-domain II of protein kinase domain (Knighton et al., 1991) (Figure $1 \mathrm{~A})$. In contrast, the catalytic lysine of WNK kinases is in sub-domain I. The amino acid of WNK1 corresponding to the catalytic lysine of PKA is cysteine (cysteine-250 in Figure $1 \mathrm{~A}$ and 2). The threeimensional structure of the WNK1 protein kinase domain, however, is similar to other protein kinases (Min et al., 2004) (Figure 2). The three-dimensional structure of the kinase domain of most protein kinases adopts a bi-lobar structure (Knighton et al., 1991). The active site of the kinase domain resides in a cleft formed by the folding domains. The catalytic lysine of WNKs and other protein kinases, despite being localized in different parts of the kinase domain, both point toward the active site in the cleft (Figure 2). WNK kinases catalyze the phosphorylation of endogenous and exogenous substrates (Xu et al., 2000, 2004; Lenertz et al., 2005; He et al., 2007). Thus, WNKs are bona fide protein kinases.

There are four mammalian WNKs (Xu et al., 2000; Verissimo and Jordan, 2001; Wilson et al., 2001). WNK1, the first member identified, is over 2100 amino acids long and contains a $\sim 270$ amino acid kinase domain located near the amino terminus (Xu et al., 2000). WNK2, 3, and 4 are products of different genes and 1200 to 1600 amino acids in length (Xu et al., 2000; Verissimo and Jordan, 2001; Wilson et al., 2001) (Figure 1B). The four WNK kinases share a conserved kinase domain with $85-90 \%$ sequence identity. In addition to the protein kinase domain, WNKs contain an autoinhibitory domain that can suppress protein kinase activity, and numerous protein-interaction motifs, including 1-2 coiled-coil domains and multiple PXXP proline-rich motifs. Little sequence identity exists beyond the above conserved domains/ motifs.

WNK proteins are ubiquitously expressed in tissues and at least some splice forms display tissue-specific expression (Xu et al., 2000; Delaloy et al., 2003; O'Reilly et al., 2003). Numerous studies in the past few years have implicated that WNK kinases play important roles in regulation of ion balance, cell signaling, survival, and proliferation, and organ development. Here, we review these studies. 
A

$\begin{array}{lll}\text { Sub-domain } & \text { I } \\ \text { PKA } & 50 & \text { GTGSE GRVMLVKHKATEQYYAMKELDKQKVVKLKQIEHTLNEKRILQAVNF } 100 \\ \text { WNK1 } & 218 & \text { GRGSE KTVYKGLDTETTVEVAWCELQDRKLTKSER-QRFKEEAEMLKGLQH } 268\end{array}$

B

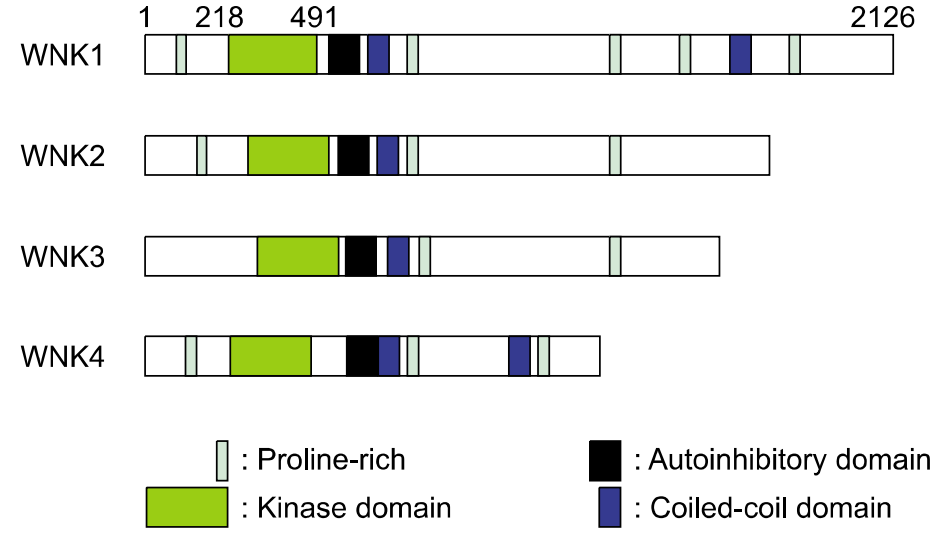

Figure 1. (A) Partial amino acid sequence of the kinase domain of PKA and WNK1. The amino acid of WNK1 corresponding to the catalytic lysine of PKA is cysteine-250 (indicated by red box). The catalytic lysine of WNK1 (lysine-233) is in the sub-domain I (indicated by green box). (B) Domain structure of WNK1-WNK4.

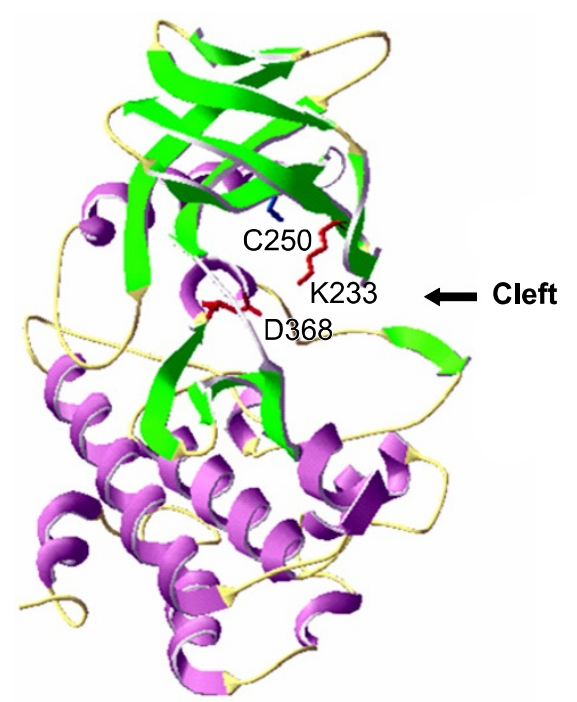

Figure 2. Crystal structure of the catalytic domain of WNK1. Ribbon representation was prepared using Deepview 3.7 based on the crystal structure solved by Min et al. (2004) (Protein Data BanK, accession code $1 \mathrm{~T} 4 \mathrm{H}$ ). Cystine-250 (blue), lysine-233, and aspartate-368 (red) are shown in ball-and-stick representation. The cleft between the N-terminal lobe (green) and C-terminal lobe (magenta) is the catalytic active site.

\section{Mutations of WNK1 and 4 cause a genetic hypertension syndrome}

Pseudohypoaldosteronism type II (PHA II), also known as Gordon's syndrome, is an autosomal-dominant disease characterized by hyper- tension, hyperkalemia, hyperchloremia, and metabolic acidosis (Gordon, 1986). Positional cloning studies have identified mutations in either WNK1 or WNK4 as causes of PHA II (Wilson et al., 2001). Disease-causing mutations in the WNK1 gene are large deletions of the first intron thought to lead to increased expression of the wild type protein and in the WNK4 gene are missense mutations in the coding sequence outside the protein kinase domain (Wilson et al., 2001). Studies on how WNK1 and 4 mutations cause PHA II have revealed important roles of WNK1 and 4 in regulating ion transport.

\section{Pathogenesis of hypertension in PHA II}

Hypertension in PHA II is associated with low plasma serum rennin levels, indicating increased $\mathrm{Na}^{+}$ retention and volume expansion (Gordon, 1986). The thiazide-sensitive $\mathrm{Na}-\mathrm{Cl}$ co-transporter (NCC) in the distal convoluted tubule accounts for $\sim 15 \%$ of sodium chloride reabsorption in the kidney. It was reported that wild type WNK4 inhibits the activity of NCC and disease-causing WNK4 mutants fail to inhibit NCC (Wilson et al., 2003; Yang et al., 2003). In addition, WNK4 phosphorylates claudins 1-4, the tight-junction proteins involved in the regulation of paracellular ion permeability (Kahle et al., 2004; Yamauchi et al., 2004). The paracellular chloride permeability is greater in cells expressing WNK4 mutants than in cells expressing wild type proteins. An increase in paracellular $\mathrm{Cl}^{-}$reabsorp- 
tion would lead to increased $\mathrm{Na}^{+}$reabsorption secondarily. These results suggest that hypertension in patients with WNK4 mutations may be caused by increased $\mathrm{NaCl}$ reabsorption through NCC and the paracellular pathway. However, hypertension in patients with WNK4 mutations was estimated to be six times more sensitive to thiazide treatment than individual with essential hypertension (Mayan et al., 2002). The increase in $\mathrm{NaCl}$ reabsorption through NCC may be relatively more important than that through the paracellular pathway. Recent studies using mice carrying a mutant WNK4 gene (created either by transgene integration or by gene knock-in) support the hypothesis that increased NCC activity is the primary cause of hypertension resulting from WNK4 mutations (Lalioti et al., 2006; Yang et al., 2007).

Expression of WNK1 abolishes inhibition of NCC caused by WNK4 in Xenopus oocytes (Yang et al., 2003), suggesting that WNK1 mutations cause hypertension by releasing WNK4-mediated inhibition of NCC in the distal convoluted tubule. However, hypertension in PHA II patients with WNK1 mutations is not particularly sensitive to thiazide diuretics (Disse-Nicodeme et al., 2000). Other mechanism(s) may also be involved. Consistent with this observation, WNK1 activates SGK1 leading to activation of the epithelial $\mathrm{Na}^{+}$channel ENaC (Xu et al., 2005a), a channel also responsible for $\mathrm{Na}^{+}$reabsorption in kidneys. Thus, hypertension in PHA II patients with WNK1 mutations may be caused by increased activity of both ENaC and NCC.

\section{Pathogenesis of hyperkalemia in PHA II}

Potassium secretion by the kidney is the primary mechanism to excrete excess $\mathrm{K}^{+}$and to maintain a normal blood $\mathrm{K}^{+}$level. ROMK $\mathrm{K}^{+}$channels in the apical membrane of the distal renal tubule are predominantly responsible for the $\mathrm{K}^{+}$secretion in the baseline (Hebert, 1995). WNK1 decreases surface expression of ROMK channels by stimulating their endocytosis via clathrin-coated vesicles (Lazrak et al., 2006; Wade et al., 2006; He et al., 2007). A decrease in renal $\mathrm{K}^{+}$secretion via ROMK1 may contribute to hyperkalemia in PHA II patients caused by WNK1 mutations.

Wild type WNK4 also decreases surface expression of ROMK1 and WNK4 mutants that cause disease exhibit a greater inhibition of ROMK (Kahle et al., 2003; He et al., 2007), suggesting that increased inhibition of ROMK1 by mutant WNK4 may also contribute to hyperkalemia in PHA II patients with WNK4 mutations. Recent studies using transgenic and knock-in mice models, however, reported no detectable difference in the expression of ROMK between wild type mice and mice carrying transgenic or knock-in WNK4 mutant (Lalioti et al., 2006; Yang et al., 2007). In the latter two reports, authors provide results to support the hypothesis that hyperkalemia in patients with WNK4 mutations is due to an increase in $\mathrm{NaCl}$ reabsorption via NCC, which causes a decrease in $\mathrm{Na}^{+}$reabsorption and secondarily impairs $\mathrm{K}^{+}$secretion at the more distal sites. Nevertheless, hyperkalemia in patients with WNK4 mutations precedes the development of hypertension (Mayan et al., 2004). It is possible that inhibition of ROMK1 by mutant WNK4 contributes to hyperkalemia in the early stage before the onset of increased NCC activity and hypertension.

\section{Full length vs kidney-specific WNK1}

There are multiple splice forms of WNKs expressed in tissue-specific patterns (Delaloy et al., 2003; O'Reilly et al., 2003). The largest WNK1 transcript encodes a polypeptide of nearly 2400 residues. A kidney-specific or KS-WNK1 is produced by replacing the first 4 exons with an alternative $5^{\prime}$ exon. Polypeptide encoded by this shorter WNK1 transcript lacks the amino terminal 437 residues of the full length form, and, as a result, has no protein kinase activity. It is expressed highly in the kidney but not elsewhere (Delaloy et al., 2003; O'Reilly et al., 2003). It was reported that the transcript encoding KS-WNK1 is more abundant than that encoding full length WNK1 in the kidney. The relative abundance of KS-WNK1 vs full length WNK1 proteins in the kidney has not been determined. Whether the large deletion of intron 1 in WNK1 in PHA II patients affects expression of KS-WNK1 is unknown. The function of KS-WNK1 has been examined. KS-WNK1 by itself has no effects on NCC and ROMK1, but antagonizes the full length WNK1-mediated regulation of NCC and ROMK (Lazrak et al., 2006; Subramanya et al., 2006; Wade et al., 2006). As a key pathway for renal $\mathrm{K}^{+}$secretion, ROMK1 is regulated by dietary $\mathrm{K}^{+}$ intake (Chu et al., 2003). Dietary $\mathrm{K}^{+}$restriction increases and decreases the expression of full length WNK1 and kidney-specific WNK1 in rat kidneys, respectively (Lazrak et al., 2006). The reciprocal effects on full-length and KS-WNK1 would amplify the inhibition of $\mathrm{K}^{+}$secretion via ROMK1, which is an expected adaptive response to reduced dietary $\mathrm{K}^{+}$intake. These results suggest that KS-WNK1 functions as a physiological antagonist of full length WNK1 with respect to its regulation of renal $\mathrm{K}^{+}$transport. 


\section{Regulation of SLC12 cation-chloride cotransporters by WNKs}

The SLC12 (solute carrier family 12 ) gene family comprises $\mathrm{Na}-\mathrm{K}-\mathrm{Cl}$ cotransporters (NKCC1 and $\mathrm{NKCC} 2$ ), $\mathrm{K}-\mathrm{Cl}$ cotransporters (KCC1-KCC4), and the thiazide-sensitive NCC (Gimenez and Forbush, 2003). In addition to the regulation of NCC as described above, WNK1, 3 and 4 increase ion transport mediated by NKCC1 and NKCC2 (Rinehart et al., 2005; Vitari et al., 2005; Anselmo et al., 2006; Gagnon et al., 2006). WNK3 and 4 also inhibit KCCs (Vitari et al., 2005; Gagnon et al., 2006; Garzon-Muvdi et al., 2007).

While NCC is present only in the distal convoluted tubule of kidney and responsible for a large portion of $\mathrm{NaCl}$ reabsorption, members of NKCC and $\mathrm{KCC}$ subfamily are widely present throughout the body. NKCCs mediate $\mathrm{Cl}^{-}$entry together with $\mathrm{Na}^{+}$and $\mathrm{K}^{+}$. In contrast, KCCs mediate $\mathrm{Cl}^{-}$exit together with $\mathrm{K}^{+}$. By controlling the intracellular concentrations of $\mathrm{Cl}^{-}$and companion cations, NKCC and $\mathrm{KCC}$ play essential roles in the regulation of neuronal excitability, cell volume, and blood pressure (Meyer et al., 2002; Kahle et al., 2005). The actions of WNKs on members of the SLC12 family in addition to NCC, both in the kidney and in other tissues, may also contribute to symptoms of PHA II. For example, NKCC1 is essential for vascular smooth muscle contraction (Meyer et al., 2002). Activation of NKCC1 by WNK1 may lead to vasoconstriction and hypertension. Moreover, increased $\mathrm{Na}^{+}$reabsorption via NKCC2 in the thick ascending limb of kidney may contribute to hypertension in patients of PHA II with WNK1 mutations.

\section{Mechanisms of regulation by WNKs}

One mechanism for WNK regulation of ion transporters is by alteration of their activity. The regulation of NKCCs by WNK1 and 4 involves two related Ste20p family protein kinases SPAK and OSR1. These protein kinases are thought to interact with and phosphorylate NKCC1, NKCC2, and NCC at their N-terminus (Piechotta et al., 2002; Gimenez and Forbush, 2003). Phosphorylation of NKCC1 is correlated with increased transporter activity. OSR1 (and SPAK) forms a tight complex with WNK1 and is directly activated by WNK1 through a catalytic mechanism (Moriguchi et al., 2005; Vitari et al., 2005, 2006; Anselmo et al., 2006). WNK4 also binds and regulates OSR 1 and SPAK (Gagnon et al., 2006). The role of SPAKI OSR1 in the regulation of KCCs by WNK3 has not been examined. The regulation of paracellular $\mathrm{Cl}^{-}$ permeability by WNK4 involves phosphorylation of the tight junction proteins claudins (Yamauchi et al., 2004).

WNKs also regulate surface expression of membrane proteins. WNK1 activates $\mathrm{ENaC}$ by preventing its endocytosis associated with a Nedd4-mediated ubiquitination (Xu et al., 2005a). WNK1 and WNK4 inhibit ROMK by stimulating endocytosis of the channel via clathrin-coated vesicles (CCV) (Kahle et al., 2003; Lazrak et al., 2006; Wade et al., 2006). One unique feature of WNK proteins is that they contain multiple PXXP motifs known for binding $\mathrm{SH} 3$ domains. A recent study ( $\mathrm{He}$ et al., 2007) reports that WNK1 and 4 stimulate CCVmediated endocytosis of ROMK by recruiting intersectin, a multimodular endocytic scafford protein containing five SH3 domains (Sengar et al., 1999). The effects of WNK1 and 4 on NCC also occur through changes of membrane expression (Yang et al., 2003; Cai et al., 2006). The precise mechanism of regulation of surface expression of NCC, though, remains unknown.

In aggregate these studies suggest that, in addition to regulating the activities of some of their transporter targets via phosphorylation, WNKs also generally act on the machinery that controls endocytosis and exocytosis of membrane transporters. WNK1 partially co-localizes with and phosphorylates synaptotagmin 2 , a protein involved in vesicle exocytosis and endocytosis (Lee et al., 2004). Phosphorylation by WNK1 changes the requirement for calcium to induce binding of synaptotagmin 2 to phospholipid vesicles. These studies suggest the potential for modulation of endocytic and/or exocytic pathways by WNKs. In support of this idea, two WNK family members, WNK2 and WNK4, were identified in an RNAi screen of human protein kinases required for clathrin- and caveolin-dependent and independent endocytosis (Pelkmans et al., 2005). The capacity to modulate membrane turnover may be essential for the breadth of transport mechanisms apparently affected by WNKs. If a more general action on membrane assembly and turnover can be substantiated, it seems likely that membrane transport and receptor systems throughout the body may be influenced by WNKs.

\section{Role of kinase domain of WNKs in the regulation of effectors}

Mutation of the catalytic lysine (lysine-233; K233) or a conserved aspartate (aspartate-368; D-368) in the kinase domain prevents WNK1 regulation of ROMK1 (Lazrak et al., 2006; Wade et al., 2006). Effects of these mutations may be due to loss of 
kinase activity and/or alteration of structure of WNKs. The crystal structure of the kinase domain of WNK1 reveals that K233 and D368 are in close proximity (Min et al., 2004) (Figure 2). He et al. (2007) reported that a WNK1 mutant carrying charge conserved substitution of lysine-233 (to arginine; K233R) regulates ROMK1 similar to the wild type WNK1. A double mutant of WNK1 carrying charge reversal mutations of K233 and D368 (K233D/D368K) also regulates ROMK1 as well as wild type WNK1 does. Both single mutant K233R and double mutant K233D/D368K lack catalytic activity. These results suggest that electrostatic interactions between K233 and D368 are critical for regulating endocytosis of ROMK1 and that kinase activity of WNK1 is not necessary for the regulation. In the same study, the authors further provide evidence supporting that a stable structure of the kinase domain (involving the interaction between K233 and D368) is critical for WNK1 to recruit intersectin through binding to PXXP motifs ( $\mathrm{He}$ et al., 2007).

\section{Upstream regulators of WNK kinases}

While the downstream targets of WNK kinases are being unraveled, their upstream regulators remain much less understood. At the moment, there are two potential physiologically important regulators of WNK1. One is hypertonicity (Xu et al., 2000; Lenertz et al., 2005). Hypertonicity stimulates autophosphorylation of WNK1 on serine-382, activating WNK1 to phosphorylate SPAK and OSR1 (Anselmo et al., 2006; Zagorska et al., 2007). SPAK and OSR1 kinase activate NKCC1 and NKCC2 by causing phosphorylation on the transporters (Moriguchi et al., 2005; Vitari et al., 2005, 2006; Anselmo et al., 2006). Hyperotonicity also induces a rapid redistribution of WNK1 from cytosol to vesicular structures (Zagorska et al., 2007). The activation of NKCC via WNK1 and SPAK/OSR1 may be important for regulatory volume increase of cells in response to hypertonicity. In hypertonic extracellular solutions, cells shrink as water leaves. Activation of NKCC increases net chloride and cation entry into cells, raising cell osmolarity and driving water reuptake.

Insulin/insulin-like growth factors (IGF) have also been implicated as upstream regulators of WNK1 (Vitari et al., 2004; Jiang et al., 2005; Xu et al., $2005 b)$. The threonine-58 of WNK1 is a phosphorylation site for Akt/protein kinase $B$, a downstream kinase of insulin/IGF pathway (Vitari et al., 2004; $\mathrm{Xu}$ et al., 2005b). Insulin and IGF1 cause phosphorylation of endogenous WNK1 at the threonine residue (Vitari et al., 2004: Jiang et al., 2005). Activation of ENaC by WNK1 via serum and glucocorticoid-inducible kinase (SGK1) depends on basal phosphorylation of threonine-58 (Xu et al., $2005 b)$. The activation of ENaC by Akt-WNK1 pathway may underlie the mechanism of sodium retention by insulin.

\section{Role of WNK1 in organ development}

WNK1 is ubiquitous (Xu et al., 2000; Delaloy et al., 2003; O'Reilly et al., 2003), raising the question of whether WNK1 plays any role in other organ systems. Support that WNK1 is involved in other organ systems comes from a recent study of mice in which the WNK1 gene has been disrupted (Zambrowicz et al., 2003). WNK1 heterozygous mice have low blood pressure. Mice homozygous for disruption of the WNK1 gene die during embryonic development before embryonic day 13 . The timing of death suggests defects in the cardiovascular development. Consistent with this possibility, Delaloy et al. (2006) reported that WNK1 expresses in the developing and adult heart and blood vessels in mice. The expression during embryonic development occurs as early as embryonic day 9.5-10.5. Analyzing embryos of time-mated WNK1-null mice, we recently found that WNK1 is indeed essential for cardiovascular development (Xie et al., 2007). These findings raise interesting questions as to whether effects of WNK1 overexpression on the cardiovascular system may contribute to hypertension in PHAll patients with WNK1 mutations. The mechanism and signaling pathways for regulation of development by WNK1 remains to be investigated.

\section{Role of WNK kinases in cell signaling, proliferation, survival, and oncogenesis}

Functions of WNK proteins in signaling, survival, and proliferation have been reported. The fly WNK (CG7177) was among molecules identified in an RNAi screen for proteins required for the survival of cultured Drosophila cells (Boutros et al., 2004). The same protein was also a strong inhibitor of signaling through the Wnt pathway, which is critical for embryonic development as well as in the adult (DasGupta et al., 2005). WNK1 activates the ERK5 MAPK signaling pathway in response to low concentrations of EGF (Xu et al., 2004). ERK5 is implicated in proliferative as well as developmental pathways, notably in cardiovascular development (Nicol et al., 2001; Yan et al., 2003). WNK3 pro- 
motes cell survival by inhibiting caspase-3 (Verissimo et al., 2006). In addition, WNKs modulate TGF $\beta$-Smad signaling (Lee et al., 2007). There are two effects of WNKs on TGF $\beta$-Smad signaling. One is to increase the cellular Smad2 level. The other is to decrease the accumulation of phosphorylated Smad2 in the nucleus, causing inhibition of Smad2-mediated transcription. The dual actions of WNKs on TGF $\beta$-Smad signaling may be relevant to the fact that TGF $\beta$ signaling can lead to both tumor suppression and progression depending the microenvironment (Derynck et al., 2001; Massague and Gomis, 2006).

Large-scale cancer genomic sequencing have identified point mutations of WNK1 in breast and colon cancer (Stephens et al., 2005; Sjoblom et al., 2006), WNK2 in lung cancer (Davies et al., 2005), and WNK1-WNK4 in a spectrum of solid tumors (Greenman et al., 2007). A recent epigenome scan has revealed that decreased WNK2 expression links to the genesis of adult infiltrative gliomas (Hong et al., 2007). Epigenome scan revealed a significant increase of aberrant methylation in contiguous CpG islands of the promoter of WNK2 in adult glioma tissues. The aberrant methylation in gliomas is associated with a reduced expression of WNK2 compared to the normal brain. Restoration of WNK2 in gloma cells by forced expression of exogenous WNK2 suppresses colony formation. Thus, WNK2 functions as a tumor suppressor for glioma cells and WNK2 silencing contributes to genesis of gliomas. Given their roles in cell survival and proliferation, connections between WNKs and oncogenesis can be anticipated to unfold in the future.

\section{Conclusion}

WNKs are expressed widely. Our knowledge of biology of WNKs and their physiological roles are limited at the present time. In the next few years the mass of information that has been and will be gathered on WNKs should help to elucidate their mechanisms of action in normal physiology and disease. In addition to the kinase domain, WNK proteins contain multiple domains for protein-protein interactions. Regulation of protein function by WNKs occurs by both catalytic and non-catalytic mechanisms. As in the above example of the role of the kinase domain of WNK1 in the regulation of ROMK1 (He et al., 2007), the role of the kinase activity of WNKs in the regulation of protein function should be carefully evaluated in each case, using experimental approaches beyond the simple tool of the kinase-dead K233 or D368 mutant.

\section{Acknowledgments}

We thank Dr. Michel Baum for critical reading and comments on the manuscript. Work from the authors' laboratories was supported by grants from the National Institutes of Health (GM53032 to MHC and DK54368 and DK59530 to $\mathrm{CLH}$ ) and the Welch Foundation (I1243 to MHC).

\section{References}

Anselmo AN, Earnest S, Chen W, Juang YC, Kim SC, Zhao $\mathrm{Y}, \mathrm{Cobb} \mathrm{MH}$. WNK1 and OSR1 regulate the $\mathrm{Na}+, \mathrm{K}+, 2 \mathrm{Cl}-$ cotransporter in HeLa cells. Proc Natl Acad Sci USA 2006;103:10883-8

Boutros M, Kiger AA, Armknecht S, Kerr K, Hild M, Koch B, Haas SA, Consortium HF, Paro R, Perrimon N. Genomewide RNAi analysis of growth and viability in Drosophila cells. Science 2004;303:832-5

Cai H, Cebotaru V, Wang YH, Zhang XM, Cebotaru L, Guggino SE, Guggino WB. WNK4 kinase regulates surface expression of the human sodium chloride cotransporter in mammalian cells. Kidney Int 2006;69:2162-70

Chu PY, Quigley R, Babich V, Huang CL. Dietary potassium restriction stimulates endocytosis of ROMK channel in rat cortical collecting duct. Am J Physiol Renal Physiol 2003;285:F1179-87

DasGupta R, Kaykas A, Moon RT, Perrimon N. Functional genomic analysis of the Wnt-wingless signaling pathway. Science 2005;308:826-33

Davies H, Hunter C, Smith R, Stephens P, Greenman C, Bignell G, Teague J, Butler A, Edkins S, Stevens C, Parker A, O'Meara S, Avis T, Barthorpe S, Brackenbury L, Buck G, Clements J, Cole J, Dicks E, Edwards K, Forbes S, Gorton M, Gray K, Halliday K, Harrison R, Hills K, Hinton J, Jones D, Kosmidou V, Laman R, Lugg R, Menzies A, Perry J, Petty R, Raine K, Shepherd R, Small A, Solomon H, Stephens $Y$, Tofts C, Varian J, Webb A, West S, Widaa S, Yates A, Brasseur F, Cooper CS, Flanagan AM, Green A, Knowles M, Leung SY, Looijenga LH, Malkowicz B, Pierotti MA, Teh BT, Yuen ST, Lakhani SR, Easton DF, Weber BL, Goldstraw P, Nicholson AG, Wooster R, Stratton MR, Futreal PA. Somatic mutations of the protein kinase gene family in human lung cancer. Cancer Res 2005;65:7591-5

Delaloy C, Lu J, Houot AM, Disse-Nicodeme S, Gasc JM, Corvol P, Jeunemaitre X. Multiple promoters in the WNK1 gene: one controls expression of a kidney-specific kinasedefective isoform. Mol Cell Biol 2003;23:9208-21

Delaloy C, Hadchouel J, Imbert-Teboul M, Clemessy M, Houot AM, Jeunemaitre X. Cardiovascular expression of the mouse WNK1 gene during development and adulthood revealed by a BAC reporter assay. Am J Pathol 2006;169: 105-18

Derynck R, Akhurst RJ, Balmain A. TGF $\beta$ signaling in tumor suppression and cancer progression. Nat Genet 2001;29: 117-29

Disse-Nicodeme S, Achard JM, Desitter I, Houot AM, 
Fournier A, Corvol $P$, Jeunemaitre $X$. A new locus on chromosome 12p13.3 for pseudohypoaldosteronism type II, an autosomal dominant form of hypertension. Am J Hum Genet 2000;67:302-10

Gagnon KB, England R, Delpire E. Volume sensitivity of cation-chloride cotransporters is modulated by the interaction of two kinases: SPAK and WNK4. Am J Physiol Cell Physiol 2006;290:C134-42

Garzon-Muvdi T, Pacheco-Alvarez D, Gagnon KB, Vazquez N, Ponce-Coria J, Moreno E, Delpire E, Gamba G. WNK4 kinase is a negative regulator of $\mathrm{K}+-\mathrm{Cl}$ - cotransporters. Am J Physiol Renal Physiol 2007;292:F1197-207

Gimenez I, Forbush B. Short-term stimulation of the renal $\mathrm{Na}-\mathrm{K}-\mathrm{Cl}$ cotransporter (NKCC2) by vasopressin involves phosphorylation and membrane translocation of the protein. J Biol Chem 2003;278:26946-51

Gordon RD. The syndrome of hypertension and hyperkalemia with normal glomerular filtration rate: Gordon's syndrome. Aust N Z J Med 1986;16:183-4

Greenman C, Stephens P, Smith R, Dalgliesh GL, Hunter C, Bignell G, Davies H, Teague J, Butler A, Stevens C, Edkins S, O'Meara S, Vastrik I, Schmidt EE, Avis T, Barthorpe S, Bhamra G, Buck G, Choudhury B, Clements J, Cole J, Dicks E, Forbes S, Gray K, Halliday K, Harrison R, Hills K, Hinton J, Jenkinson A, Jones D, Menzies A, Mironenko T, Perry J, Raine K, Richardson D, Shepherd R, Small A, Tofts C, Varian J, Webb T, West S, Widaa S, Yates A, Cahill DP, Louis DN, Goldstraw P, Nicholson AG, Brasseur F, Looijenga L, Weber BL, Chiew YE, DeFazio A, Greaves MF, Green AR, Campbell P, Birney E, Easton DF, Chenevix-Trench G, Tan MH, Khoo SK, Teh BT, Yuen ST, Leung SY, Wooster R, Futreal PA, Stratton MR. Patterns of somatic mutation in human cancer genomes. Nature 2007;446:153-8

He G, Wang HR, Huang SK, Huang CL. Intersectin links WNK kinases to endocytosis of ROMK1. J Clin Invest 2007;117: 1078-87

Hebert SC. An ATP-regulated, inwardly rectifying potassium channel from rat kidney (ROMK). Kidney Int 1995;48:1010-6

Hong C, Moorefield KS, Jun P, Aldape KD, Kharbanda S, Phillips HS, Costello JF. Epigenome scans and cancer genome sequencing converge on WNK2, a kinase-independent suppressor of cell growth. Proc Natl Acad Sci USA 2007;104:10974-9

Jiang ZY, Zhou QL, Holik J, Patel S, Leszyk J, Coleman K, Chouinard M, Czech MP. Identification of WNK1 as a substrate of Akt/protein kinase $B$ and a negative regulator of insulin-stimulated mitogenesis in 3T3-L1 cells. J Biol Chem 2005;280:21622-8

Kahle KT, Wilson FH, Leng Q, Lalioti MD, O'Connell AD, Dong K, Rapson AK, MacGregor GG, Giebisch G, Hebert SC, Lifton RP. WNK4 regulates the balance between renal $\mathrm{NaCl}$ reabsorption and K+ secretion. Nat Genet 2003;35: 372-6

Kahle KT, MacGregor GG, Wilson FH, Van Hoek AN, Brown D, Ardito T, Kashgarian M, Giebisch G, Hebert SC, Boulpaep EL, Lifton RP. Paracellular Cl- permeability is regulated by WNK4 kinase: insight into normal physiology and hyper- tension. Proc Natl Acad Sci USA 2004;101:14877-82

Kahle KT, Rinehart J, de Los HP, Louvi A, Meade P, Vazquez N, Hebert SC, Gamba G, Gimenez I, Lifton RP. WNK3 modulates transport of $\mathrm{Cl}$ - in and out of cells: Implications for control of cell volume and neuronal excitability. Proc Natl Acad Sci USA 2005;102:16783-8

Knighton DR, Zheng JH, Ten Eyck LF, Ashford VA, Xuong NH, Taylor SS, Sowadski JM. Crystal structure of the catalytic subunit of cyclic adenosine monophosphate-dependent protein kinase. Science 1991;253:407-14

Lalioti MD, Zhang J, Volkman HM, Kahle KT, Hoffmann KE, Toka HR, Nelson-Williams C, Ellison DH, Flavell R, Booth CJ, Lu Y, Geller DS, Lifton RP. Wnk4 controls blood pressure and potassium homeostasis via regulation of mass and activity of the distal convoluted tubule. Nat Genet 2006;38:1124-32

Lazrak A, Liu Z, Huang CL. Antagonistic regulation of ROMK by long and kidney-specific WNK1 isoforms. Proc Natl Acad Sci USA 2006;103:1615-20

Lee BH, Min X, Heise CJ, Xu B, Chen S, Shu H, Luby-Phelps K, Goldsmith EJ, Cobb MH. WNK1 phosphorylates synaptotagmin 2 and modulates its membrane binding. Molecular Cell 2004;15:741-51

Lee BH, Chen W, Stippec S, Cobb MH. Biological Cross-talk between WNK1 and the Transforming Growth Factor beta-Smad Signaling Pathway. J Biol Chem 2007;282: 17985-96

Lenertz L, Lee BH, Min X, Xu B, Wedin K, Earnest S, Goldsmith EJ, Cobb MH. Properties of WNK1 and implications for other family members. J Biol Chem 2005;280: 26653-8

Massague J, Gomis RR. The logic of TGF $\beta$ signaling. FEBS Lett 2006;580:2811-20

Mayan H, Vered I, Mouallem M, Tzadok-Witkon M, Pauzner R, Farfel Z. Pseudohypoaldosteronism type II: marked sensitivity to thiazides, hypercalciuria, normomagnesemia, and low bone mineral density. J Clin Endocrinol Metab 2002; 87:3248-54

Mayan H, Munter G, Shaharabany M, Mouallem M, Pauzner R, Holtzman EJ, Farfel Z. Hypercalciuria in familial hyperkalemia and hypertension accompanies hyperkalemia and precedes hypertension: description of a large family with the Q565E WNK4 mutation. J Clin Endocrinol Metab 2004;89: 4025-30

Meyer JW, Flagella M, Sutliff RL, Lorenz JN, Nieman ML, Weber CS, Paul RJ, Shull GE. Decreased blood pressure and vascular smooth muscle tone in mice lacking basolateral $\mathrm{Na}(+)-\mathrm{K}(+)-2 \mathrm{Cl}(-)$ cotransporter. Am J Physiol Heart Circ Physiol 2002;283:H1846-55

Min X, Lee BH, Cobb MH, Goldsmith EJ. Crystal structure of the kinase domain of WNK1, a kinase that causes a hereditary form of hypertension. Structure 2004;12:1303-11

Moriguchi T, Urushiyama S, Hisamoto N, lemura S, Uchida $\mathrm{S}$, Natsume T, Matsumoto K, Shibuya H. WNK1 regulates phosphorylation of cation-chloride-coupled cotransporters via the STE20-related kinases, SPAK and OSR1. J Biol Chem 2005;280:42685-93 
Nicol RL, Frey G, Pearson G, Cobb M, Richardson J, Olson EN. Activated MEK5 induces serial assembly of sarcomeres and eccentric cardiac hypertrophy. EMBO J 2001;20:275767

O'Reilly M, Marshall E, Speirs HJ, Brown RW. WNK1, a gene within a novel blood pressure control pathway, tissuespecifically generates radically different isoforms with and without a kinase domain. J Am Soc Nephrol 2003;14: 2447-56

Pelkmans L, Fava E, Grabner H, Hannus M, Habermann B, Krausz E, Zerial M. Genome-wide analysis of human kinases in clathrin- and caveolae/raft-mediated endocytosis. Nature 2005;436:78-86

Piechotta K, Lu J, Delpire E. Cation chloride cotransporters interact with the stress-related kinases Ste20-related proline-alanine-rich kinase (SPAK) and oxidative stress response 1 (OSR1). J Biol Chem 2002;277:50812-9

Rinehart J, Kahle KT, de Los HP, Vazquez N, Meade P, Wilson FH, Hebert SC, Gimenez I, Gamba G, Lifton RP. WNK3 kinase is a positive regulator of NKCC2 and NCC, renal cation-Cl- cotransporters required for normal blood pressure homeostasis. Proc Natl Acad Sci USA 2005;102:16777-82

Sengar AS, Wang W, Bishay J, Cohen S, Egan SE. The EH and $\mathrm{SH} 3$ domain Ese proteins regulate endocytosis by linking to dynamin and Eps15. EMBO J 1999;18:1159-71

Sjoblom T, Jones S, Wood LD, Parsons DW, Lin J, Barber TD, Mandelker D, Leary RJ, Ptak J, Silliman N, Szabo S, Buckhaults P, Farrell C, Meeh P, Markowitz SD, Willis J, Dawson D, Willson JK, Gazdar AF, Hartigan J, Wu L, Liu C, Parmigiani G, Park BH, Bachman KE, Papadopoulos N, Vogelstein B, Kinzler KW, Velculescu VE. The consensus coding sequences of human breast and colorectal cancers. Science 2006;314:268-74

Stephens P, Edkins S, Davies H, Greenman C, Cox C, Hunter C, Bignell G, Teague J, Smith R, Stevens C, O'Meara S, Parker A, Tarpey P, Avis T, Barthorpe A, Brackenbury L, Buck G, Butler A, Clements J, Cole J, Dicks E, Edwards K, Forbes S, Gorton M, Gray K, Halliday K, Harrison R, Hills K, Hinton J, Jones D, Kosmidou V, Laman R, Lugg R, Menzies A, Perry J, Petty R, Raine K, Shepherd R, Small A, Solomon H, Stephens Y, Tofts C, Varian J, Webb A, West S, Widaa S, Yates A, Brasseur F, Cooper CS, Flanagan AM, Green A, Knowles M, Leung SY, Looijenga LH, Malkowicz B, Pierotti MA, Teh B, Yuen ST, Nicholson AG, Lakhani S, Easton DF, Weber BL, Stratton MR, Futreal PA, Wooster R. A screen of the complete protein kinase gene family identifies diverse patterns of somatic mutations in human breast cancer. Nat Genet 2005;37:590-2

Subramanya AR, Yang CL, Zhu X, Ellison DH. Dominantnegative regulation of WNK1 by its kidney-specific kinasedefective isoform. Am J Physiol Renal Physiol 2006;290: F619-24

Verissimo F, Jordan P. WNK kinases, a novel protein kinase subfamily in multi-cellular organisms. Oncogene 2001;20: 5562-9

Verissimo F, Silva E, Morris JD, Pepperkok R, Jordan P. Protein kinase WNK3 increases cell survival in a caspase- 3-dependent pathway. Oncogene 2006;25:4172-82

Vitari AC, Deak M, Collins BJ, Morrice N, Prescott AR, Phelan A, Humphreys $S$, Alessi DR. WNK1, the kinase mutated in an inherited high-blood-pressure syndrome, is a novel PKB (protein kinase B)/Akt substrate. Biochem J 2004;378:25768

Vitari AC, Deak M, Morrice NA, Alessi DR. The WNK1 and WNK4 protein kinases that are mutated in Gordon's hypertension syndrome phosphorylate and activate SPAK and OSR1 protein kinases. Biochem J 2005;391:17-24

Vitari AC, Thastrup J, Rafiqi FH, Deak M, Morrice NA, Karlsson HK, Alessi DR. Functional interactions of the SPAK/OSR1 kinases with their upstream activator WNK1 and downstream substrate NKCC1. Biochem J 2006;397: 223-31

Wade JB, Fang L, Yang CL, Subramanya AR, Maouyo D, Mason A, Ellison DH, Welling PA. WNK1 kinase isoform switch regulates renal potassium excretion. Proc Natl Acad Sci USA 2006;103:8558-63

Wilson FH, Disse-Nicodeme S, Choate KA, Ishikawa K, Nelson-Williams C, Desitter I, Gunel M, Milford DV, Lipkin GW, Achard JM, Feely MP, Dussol B, Berland Y, Unwin RJ, Mayan H, Simon DB, Farfel Z, Jeunemaitre X, Lifton RP. Human hypertension caused by mutations in WNK kinases. Science 2001;293:1107-12

Wilson FH, Kahle KT, Sabath E, Lalioti MD, Rapson AK, Hoover RS, Hebert SC, Gamba G, Lifton RP. Molecular pathogenesis of inherited hypertension with hyperkalemia: The Na-Cl cotransporter is inhibited by wild-type but not mutant WNK4. Proc Natl Acad Sci USA 2003;100:680-4

Xie J, Wu T, Cleaver O, Huang CL. WNK1 is essential for cardiovascular development in mice. J Am Soc Nephrol (Abstract) 2007 (in press)

Xu B, English JM, Wilsbacher JL, Stippec S, Goldsmith EJ, Cobb $\mathrm{MH}$. WNK1, a novel mammalian serine/threonine protein kinase lacking the catalytic lysine in subdomain II. J Biol Chem 2000;275:16795-801

Xu B, Stippec S, Lenertz L, Lee BH, Zhang W, Lee YK, Cobb $\mathrm{MH}$. WNK1 activates ERK5 by an MEKK2/3-dependent mechanism. J Biol Chem 2004;279:7826-31

Xu B, Stippec S, Chu PY, Li XJ, Lazrak A, Ortega B, Lee BH, English JM, Huang CL, Cobb MH. WNK1 activates SGK1 to regulate the epithelial sodium channel. Proc Natl Acad Sci USA 2005a;102:10315-20

Xu B, Stippec S, Lazrak A, Huang CL, Cobb MH. WNK1 activates SGK1 by a PI-3 kinase-dependent and noncatalytic mechanism. J Biol Chem 2005b;280:34218-23

Yamauchi K, Rai T, Kobayashi K, Sohara E, Suzuki T, Itoh T, Suda S, Hayama A, Sasaki S, Uchida S. Disease-causing mutant WNK4 increases paracellular chloride permeability and phosphorylates claudins. Proc Natl Acad Sci USA 2004;101:4690-4

Yan L, Carr J, Ashby PR, Murry-Tait V, Thompson C, Arthur JS. Knockout of ERK5 causes multiple defects in placental and embryonic development. BMC Dev Biol 2003;3:11

Yang CL, Angell J, Mitchell R, Ellison DH. WNK kinases 
regulate thiazide-sensitive $\mathrm{Na}-\mathrm{Cl}$ cotransport. J Clin Invest 2003;111:1039-45

Yang SS, Morimoto T, Rai T, Chiga M, Sohara E, Ohno M, Uchida K, Lin SH, Moriguchi T, Shibuya H, Kondo Y, Sasaki $\mathrm{S}$, Uchida S. Molecular pathogenesis of pseudohypoaldosteronism type II: generation and analysis of a Wnk4 (D561A/+) knockin mouse model. Cell Metab 2007;5:331-44

Zagorska A, Pozo-Guisado E, Boudeau J, Vitari AC, Rafiqi FH, Thastrup J, Deak M, Campbell DG, Morrice NA, Prescott $A R$, Alessi DR. Regulation of activity and localization of the WNK1 protein kinase by hyperosmotic stress. J Cell Biol
2007; $176: 89-100$

Zambrowicz BP, Abuin A, Ramirez-Solis R, Richter LJ, Piggott J, BeltrandelRio H, Buxton EC, Edwards J, Finch RA, Friddle CJ, Gupta A, Hansen G, Hu Y, Huang W, Jaing C, Key BW Jr, Kipp P, Kohlhauff B, Ma ZQ, Markesich D, Payne R, Potter DG, Qian N, Shaw J, Schrick J, Shi ZZ, Sparks MJ, Van Sligtenhorst I, Vogel P, Walke W, Xu N, Zhu Q, Person C, Sands AT. Wnk1 kinase deficiency lowers blood pressure in mice: A gene-trap screen to identify potential targets for therapeutic intervention. Proc Natl Acad Sci USA 2003;100: 14109-14 